lencio de criterio en la selección de los fragmentos.

En definitiva, nos hallamos ante un instrumento que, aparte de los puntos que he considerado negativos, puede ser empleado con gran utilidad. Como supongo que será bienven(d)ido y reeditado, es de esperar que los pequeños puntos negros vayan desapareciendo.

JUAN Victorio

\section{TEXTOS TEATRALES}

\section{HISPANICOS DEL SIGLO XVI}

FerRer Valls, Teresa: Nobleza y espectáculo teatral (1535-1622). Estudio y documentos. Valencia: UNED/Universidad de Sevilla/Universitat de València, 1993, 392 pp. (Textos teatrales hispánicos del siglo XVI; 1). Canet Vallé, José LUIS, De la comedia humanistica al teatro representable (Égloga de la tragicomedia de Calisto y Melibea, Penitencia de amor, Comedia Thebayda, Comedia Hipólita. Comedia Serafina). Valencia: UNED/Universidad de Sevilla/Universitat de València, 1993, 392 pp. (Textos teatrales hispánicos del siglo XVI; 2). PErez PRIEGo, Miguel ANGel, Cuatro comedias celestinescas. Valencia: UNED/Universidad de Sevilla/ Universitat de València, 1993, 392 pp. (Textos teatrales hispánicos del siglo XVI; 3).

Se ha inaugurado con fuerza una nueva colección dedicada, como su tí- tulo explicita, a la edición de textos teatrales del siglo XVI. Y empieza pisando fuerte, ya que las obras que la inauguran son de tres reconocidos especialistas en la materia con un abundante bagaje de estudios sobre el tema a sus espaldas. Además garantiza su calidad actual y futura el que su director sea Joan Oleza y que el comité asesor esté formado por M. A. Pérez Priego, M. de los Reyes Peña y J. L. Sirera, pertenecientes a las tres universidades que con un empuje digno de ser imitado han unido sus fuerzas para sacar adelante las ediciones.

Como no podía ser menos, las criaturas fruto de tales labores alcanzan el nivel esperable y exigible a sus autores, lo que hace que textos y estudios sean en el futuro básicos para investigadores o incluso simples interesados. Por otro, lado al emplear un enfoque diverso, su complementariedad nos ayuda a entrever mejor un panorama que solemos contemplar fragmentariamente. M. T. Ferrer se ocupa de la representación y el espectáculo cortesano, en el cual el texto tiene una importancia secundaria frente al fasto; J. L. Canet y M. A. Pérez Priego dedican sus esfuerzos al texto literario, valioso con independencia de su puesta en escena.

En el primero de los libros, el presupuesto teórico del que parte M. T. Ferrer para desarrollar su investigación es la comprensión del hecho teatral como un todo que engloba texto, representación en su conjunto y público; así el historiador del teatro se 
ha de ocupar también de «las noticias descriptivas que se puedan ir acumulando sobre representaciones y espectáculos teatrales, o sobre cualquiera aspecto de infraestructura teatral» (p. 11). Así pues, su obra no escoge los textos por su valor literario, sino documental, buscando hacer patente la evolución de las técnicas escenográficas desde 1535 a 1622 , entre las representaciones descritas en $\mathrm{El}$ cortesano, de Luis Milán y las que bajo el reinado de Felipe IV son dirigidas por escenógrafos italianos.

E1 estudio introductorio no se limita a estas cuestiones. Aunque se destaca la escasez de relaciones en que se describen también los espectáculos teatrales cortesanos, son suficientes para entrever un panorama mucho más rico que el sostenido por la crítica tradicional. Las fiestas conocidas se desarrollan principalmente en dos cortes: la virreinal de Valencia y la española; en ambas se puede observar que los espectáculos más frecuentes son los torneos (éstos alcanzan un alto grado de dramatización con incorporación de personajes de libros de caballerías) y las máscaras, cuyos componentes esenciales son el disfraz, la música y el gesto. Su espacio son las salas y patios interiores y los jardines donde se montan teatros efímeros. Así la autora ha sabido extraer de los documentos que edita un panorama que reconstruye ante nuestros ojos y que enlaza con los orígenes medievales, por un lado, y con las in- novaciones introducidas por los maestros italianos, por otro.

A partir de este punto la introducción da un giro para llevarnos al estudio del encargo de la Historial alfonsina a Lope de Vega, empleando dos manuscritos, uno de la Biblioteca Nacional de Madrid y el otro de la Academia de la Historia, trabajados por J. Oleza y por la propia M. T. Ferrer. Ahora se editan ambos y se analizan minuciosamente. El planteamiento arranca del estudio de los antecedentes del drama histórico barroco, su dependencia del mecenazgo al considerarlo un vehículo de transmisión ideológica, Lope de Vega como autor de comedias genealógicas y el encargo que se le hizo de esta obra. Pasa luego a tratar pormenorizadamente sólo de estos manuscritos y lo que implican, descripción de los mismos, análisis de su contenido, las circunstancias del encargo, los litigios de D. Francisco de Aragón para esclarecer qué fin perseguía con tal comisión, su ascendencia, etc. Se completa comentando las notas hechas por Lope para adaptar el material histórico que se le ha suministrado a la escena.

No cabe duda de la trascendencia del testimonio, que demuestra hasta qué punto pudo influir el mecenazgo en determinado tipo de producción literaria. Desde luego este sistema es parte de los vínculos que se establecen entre nobleza y autor teatral/obra de teatro y desde esta perspectiva cabe bajo el título del libro. No obstante, el entusiasmo de la autora le ha 
llevado a perder tal perspectiva del conjunto al dedicar casi la mitad del estudio a la Historial alfonsina, lo que no menoscaba en absoluto la excelente calidad del trabajo, pero le hace sentir al lector que se trata de dos partes desiguales con la balanza inclinada a favor de la segunda.

Desde el principio declaraba M. T. Ferrer que algunos de los textos que edita son conocidos y otros no, aunque en general son de difícil consulta. Si están ahí reunidos no es tanto porque describan fiestas privadas o espectáculos cortesanos, puesto que hay salvedades, sino porque sirven para «ir recomponiendo un panorama que todavía conocemos mal, el de la evolución de las técnicas escenográficas» (p. 94). En su edición los criterios se han atendido al máximo, y las notas que los acompañan son generosas y bien seleccionadas, aspectos que sorprenden muy gratamente cuando $\tan$ frecuente es que se descuiden en este género de recopilaciones. La bibliografía es muy completa y bien seleccionada.

En el segundo de los estudios que aquí se reseña, $L$. Canet edita cinco piezas dramáticas, si bien de la Comedia Thebayda, al ser muy larga, sólo algunos fragmentos. Su introducción, planteada de forma muy clara y concisa, desarrolla una buena síntesis de que fue la comedia humanística, su origen, retórica, finalidad moral y didáctica y modo de difusión, mostrando el profundo conocimiento que el autor tiene del tema. Las comedias es- critas en castellano se encuentran vinculadas en alguna medida a la Celestina y pueden clasificarse en dos grupos: el que depende directamente de esa obra, que parece relacionarse con Salamanca; el que está formado por obras que siguen la comedia clásica y que se encuentran más próximas al espíritu docente, ligadas a Zaragoza y Valencia. Sobre éstas versa el resto de su estudio.

Bajo el epígrafe «Hacia la representación» se incluyen dos obras que J. L. Canet considera ejercicios estudiantiles. Una, la Egloga de Calisto y Melibea, servirá de práctica a Pedro Manuel de Urrea para dominar la escena y puede que se representara ante su madre, a quien va dedicada. La otra, la Comedia Hypólita, será un intento fallido de su anónimo autor que imitando a Torres Naharro y copiando muy de cerca la Thebayda y la Serafina no domina la técnica representativa ni los mecanismos del teatro. «Otros experimentos» serán La penitencia de amor, La comedia Thebayda y la Comedia Serafina. La primera, al mezclar la ficción sentimental (Carcel de amor) con la comedia (Celestina), es una amalgama de difícil clasificación en la que junto al diálogo se insertan cartas y poesías. A la segunda su carga retórica y didáctica y los temas que baraja le hacen considerarla similar a un manual de educación de príncipes. La tercera, la Comedia Serafina, se halla mucho más próxima al modelo «comedia humanística» y se parece a las que se escri- 
bían en Italia a finales del 400 o principios del 500.

Estas cinco obras comparten una serie de características generales que se examinan a continuación: la trama o argumento, donde siempre está presente el deseo amoroso con un final feliz o al menos no desgraciado; los personajes, tipos representativos de una clase general a la que se critica; y la técnica compositiva dramática, apartes y conversaciones dobles o cruzadas y tiempo y espacio muy reducidos. No cabe duda de que en estos aspectos se acercan al teatro representable, pero me pregunto si -con excepción de la Egloga de Urrea- efectivamente lo fueron y dónde, ¿Qué publico pudieron tener? ¿Fue sólo lector? ¿Qué lectores? ¿Por qué esa primera edición de Valencia 1521 tan rara? ¿Por qué una edición en Sevilla en 1546 sin la Ypólita?

Es abundante la bibliografía final, aunque conviene advertir que no se recogen en ella todas las obras que están citadas en las notas a pie de página. Hay algún descuido en los criterios de edición, donde falta el año de la impresión del Cancionero de Urrea (1513) y el del artículo de Hathaway en la NRFH (1978); la edición de de R. Foulché Delbosc de la Penitencia (Barcelona/Madrid, L'Avenç/Librería Murillo, 1902), y la de G. D. Trotter y $\mathrm{K}$. Whinnom (Londres, Tamesis Books, 1968), ausencias que se deben con seguridad a la premura con que se suelen terminar los trabajos. Por último, en lo que se refiere al criterio c),
«Introducción de aquellas partículas omitidas en el texto, como $a$, de, que, etcétera, para una mejor comprensión del texto, colocándolas entre corchetes» (p. 80) ${ }^{3}$, lo encuentro correcto en muchas ocasiones, pero discrepo en otras. Pequeños inconvenientes que no empañan para nada la calidad del conjunto y la satisfacción que se siente ante la lectura de un trabajo valioso.

El tercero de los libros le sirve a M. A. Pérez Priego para editar cuatro obras en las que viene trabajando desde hace algún tiempo, aunque siempre desde el punto de vista crítico y hasta ahora no editorial. Así, a la vez que culmina una investigación, nos ha acercado cuatro textos cuyas ediciones «modernas» son apenas accesibles: Comedia intitulada Tesorina, Comedia llamada Tidea, Auto llamado Clarindo, y Comedia Pródiga. La introducción se centra en examinar cómo Celestina fecundó el teatro del siglo XVI, y así establecer a una definición: «La que llamamos "comedia celestinesca" no la entendemos, en realidad, como un género aparte de ese teatro. Lo celestinesco creemos que es aquí, más que nada un fermento, un estímu-

${ }^{3}$ Me refiero a casos como el de la página 151: «me sirven con otra manera de amor que [la que] tú dizes», donde el texto me parece perfectamente correcto sin que sea necesario hacer diciones. Asimismo creo que el empleo de las formas del verbo llevar sin palatalización inicial (Il]levar, p. 133), [l]levado, p. 137) es el habitual en los textos de la época y no necesita ninguna corrección. 
lo y un conjunto de posibilidades argumentales, a las que a veces recurren dramaturgos de la época» (p. 11). Ahora bien, Celestina no era representable, así que para poder ponerse en escena estas obras introducirán a partir del modelo una serie de modificaciones: sólo un personaje o grupo de ellos; trama argumental reducida con final feliz; escenario urbano, pero sin ambiente prostibulario; ausencia de diálogos oratorios. Relacionadas con Celestina se tratan individualmente: la Egloga de Plácida y Victoriano donde Encina introduciendo a la alcahueta pretende adecuarse a la modernidad; la Egloga de la tragicomedia de Calisto y Melibea, que a J. L. Canet también le parecía un intento de renovar la égloga; la Himenea de Torres Naharro, donde el planteamiento inicial es igual que en Celestina, pero se separa en la ausencia de mediadora y en el final feliz; la Comedia Ypólita, que desarrolla unos amores sin ningún impedimento. Estas influencias se detienen desde mediados de siglo en adelante, porque no se registran ni en Rueda ni en Timoneda (aunque sí haya rasgos en $E l$ infamador de Juan de la Cueva y en la Comedia Salvaje de Joaquín Romero de Cepeda) y menos aún después con la implantación del teatro en verso.

Cada una de las comedias que se editan a continuación recibe un comentario más detallado, pero aunque se hable de su autor, ediciones y fortuna crítica, nunca se pierde de vista la relación con lo celestinesco, en unos casos por presencia y en otros por ausencia. Como en los otros dos libros de la colección, la introducción se cierra con unas fuentes textuales en las que se efectúan unas cuidadosas descripciones bibliográficas de las obras y una bibliografía que denota al especialista en el tema.

Es obligación ineludible de todo reseñador que se precie revisar la bibliografía y encontrar algo que añadir al descuido, olvido u omisión voluntaria de los autores. No rehuiré mi obligación y citaré primero dos tesis doctorales recientes por tratarse de trabajos valiosos y poco mencionados: L. M. Esteban Martín, Edición y estudio de la «Tragedia Policiana» de Sebastián Fernández, Madrid, Universidad Complutense, 1992; y M. M. García-Bermejo Giner, Introducción a la farsa renacentista, Salamanca, Universidad, 1992. Ahora tres trabajos que, con alguna rebusca, he advertido que no están incluidos: $R$. de Andrés Díaz, «Fiestas y espectáculos en las Relaciones góticas del siglo XVI», En la España medieval, XIV (1991), pp. 325-46; Ph. Berger, Libro y lectura en la Valencia del Renacimiento, Valencia, Edicions Alfons el Magnànim, 1987, 2 vols.; y E. Nagy, El prodigo y el pícaro. La escuela de la vida en el Siglo de Oro español, Valladolid, Editorial Sever-Cuesta, 1974.

NIEVES BARANDA UNED 